\title{
Development of Transient Damage Behaviors of Copper Alloys under High Velocity Sliding Electrical Contact
}

\author{
Bao-Yu ZHANG ${ }^{1,{ }^{*}}$, Xin-Ge GUO ${ }^{2,3}$, Wei HUANG ${ }^{1,4}$, Wei-Ming HUANG ${ }^{1}$ \\ ${ }^{1}$ Ning bo Branch of China Academy of Ordnance Science, Ningbo 315103, China; \\ ${ }^{2}$ Institute of Solid State Physics, Chinese Academy of Sciences, Hefei 230031, China \\ ${ }^{3}$ University of Science and Technology of China, Hefei 230026, China \\ ${ }^{4}$ Ningbo University, Ning bo 315211, China; \\ *byzhang@outlook.com \\ ${ }^{*}$ Corresponding author: Bao-Yu ZHANG
}

Keywords: Sliding electrical contact, Copper alloys, Transient damage

\begin{abstract}
The transient damage problems of copper alloys are the central topic for improving the accuracy and lifetime of electromagnetic launcher. The research works on transient damage behaviors of copper alloys under high-speed sliding electrical contact during the past two decades were summarized in this paper and some suggestions for future research were presented. Firstly the three damage forms of copper alloys under high-velocity sliding electrical contact were introduced, respectively. Then the main technical methods that can solve the damage problems of copper alloys were presented. Finally some proposals for further study on transient damage behavior of copper alloys under sliding electrical contact were put forward.
\end{abstract}

\section{Introduction}

Surface transient damage problems of copper alloys under high-velocity sliding electrical contact, especially in electromagnetic launching, lead to deterioration of the lifetime and accuracy of the launcher. During electromagnetic launching, the friction types of sliding electrical contact change with the increment of armature velocity, transferring from arc erosion to mechanical wear, melt wear and impact. Meanwhile, the damage forms of copper alloys change with the increment of armature velocity, transferring from arc erosion to edge grooving and hypervelocity gouging. Up to now, some important progress has been made on transient damage problems of copper alloys.

Most studies on damage of copper alloys tried to establish the coupling effect of electromagnetic, stress and temperature fields between armature and rails during electromagnetic launching using simulation analysis methods. Then the coupled physical fields were used to understand the damage characteristics of copper alloys, such as damage types, spatial distribution and evolution process. Surface coating hardening treatment was extensively studied to enhance the erosion resistance ability of copper alloys. Based on the multi-shot tests, the surface profile, micro structural characteristics and hardness of grooving of copper alloys had been determined and analyzed to reveal how material properties and launching conditions affect the grooving forming. Material properties and surface defects on the threshold velocity of gouging were also investigated to reduce the impact of gouging on copper alloys. In this paper, the research works and technical solutions on transient damage problems of copper alloys under high-velocity sliding electrical contact during the past two decades were summarized and some suggestions for future research were presented.

\section{The Surface Transient Damage of Copper Alloys during Electromagnetic Launching}

\section{The Grooving of Coppe $r$ Alloys during Electromagnetic Launching}

Grooving on copper alloys was reported for the first time byGeeet al.[1]in multipleelectromagnetic launching. Groovesinitiated approximately $35 \mathrm{~mm}$ from the starting position, and were sharp groove shape and $62.8 \mu \mathrm{m}$ deep. Poor thermal and electrical conductivities may be responsible for severer 
damage of $\mathrm{Be}-\mathrm{Cu}$ alloy relative to other tested alloys. Watt et al. [2] discovered that there were two kinds of grooving damage types: the well-defined grooves and the less defined grooves. The less defined grooves are about $5 \mathrm{~mm}$ wide and $0.5 \mathrm{~mm}$ deep. Megeret al. [3] found that the grooving damage on copper alloys often occurs in the first half of rails. The energy dispersive spectrum results of the deposited layer of one-shot show that the top layer is carbon-rich and silicon-rich; the middle layer is Al-rich cellular-dendrites and inter-cellular $\mathrm{Al}_{2} \mathrm{Cu}$; the layer closest to the copper alloys is $\mathrm{Cu}$-rich dendrites. In 20-shots, the microstructure of the deposited layer is varying scale of cellular-dendritic microstructures.

Materials surface softening and the erosion of molten aluminum are the two main physical mechanisms responsible for grooving forming. In 2007, Wattet al. [2] observed the less defined grooves at 30 centimeter from the starting position. Watt concluded the dissolution of copper alloys by molten aluminum facilitated by resistive heating, was responsible for grooving forming. Cooperet al. [4] discovered that the maximum grooving depth located at the edge of insulation materials, spreading towards the center and edge of rails. Cooper concluded that grooving forming originated from the dissolution of copper alloys because of the flow of high velocity and high temperature molten aluminum as a result of velocity skin effect. After conducting 20 times launches, Megeret al. [3] concluded that the grooving depth linearly increased with the increment of the number of shots.

\section{The Gouging of Copper Alloys during Electromagnetic Launching}

Gouging is a surface damage phenomenon that usually occurs in high velocity sliding contacts. Gouging craters are typically teardrop shaped and about $1-3 \mathrm{~cm}$ in length and $1-2 \mathrm{~cm}$ in depth. The typical morphology of a typical gouging crater is shown in Fig. 1. It is noticed that significant hump of the rail is observed in front of the gouging crater, indicating the rail undergoing severe plastic deformation. In 2012, Zhu et al. [5] performed composition analysis and metallographic observation on gouging craters. It was found that the main chemical compositions of gouging craters include carbon, oxygen, aluminum, copper and zinc. The internal morphology of gouging craters were tearing edge, recrystallizationmorphology and scratch, which indicated the interface between armature and rails underwent severe plastic deformation and temperature rising.

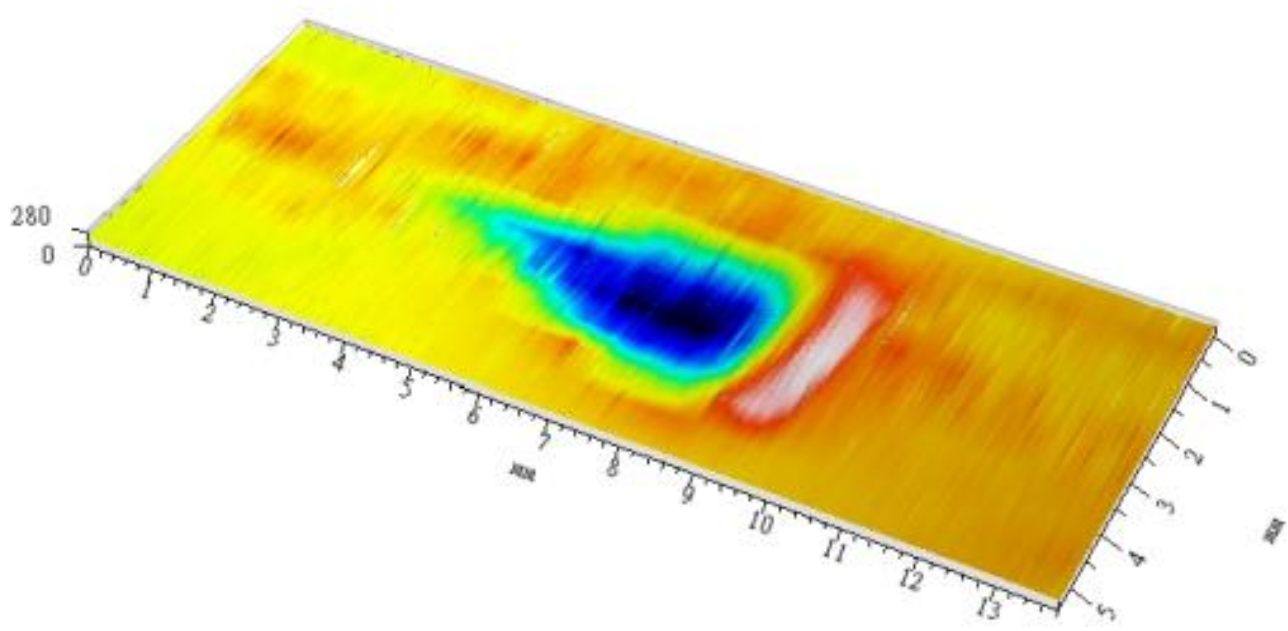

Fig. 1 Optical profilometry image of a typical gouge crater

The gouging forming mechanism and the affecting factors of gouging threshold velocity were extensively studied on gouging damage of rails. In general, the gouging threshold velocity is affected by friction pairs and material properties of armature and rails. In 1999, Stefani and Parker [6] conducted tests on C1100 rails with different armature materials. It was found that the gouging threshold velocity increased with the increment of hardness of armatures, meanwhile, the hardness 
of the harder materials $\mathrm{H}$ and the normal shock pressure $\mathrm{P}$ showed a linear correlation: $\mathrm{P}=0.073 \mathrm{H}+9.343$. Tarczaet al. [7] found that harder of rail materials can result in higher gouging threshold velocity with the same armature materials. AFIT found that the ratio of yield strength and density can be fitted with linear correlation with gouging threshold velocity. Gouging can be prevented by using armature materials with higher yield strength and low density. In 2014, Watt [8] et al. conducted electromagnetic launching on flat and indented copper rails and examined the effect of surface indentations on gouging onset velocity and morphology. It was found that surface indentations had little effect on gouging onset velocity. However, the gouging craters morphology could be obviously changed.

The first model of gouging was proposed by Baber [9], which described gouging as a process of surface asperities interacting with armatures at high velocity. From calculated results, the gouging threshold velocity was determined by density, yield strength, the angle of attack and bulk wave velocity. Higher yield strength and lower angle of attack can weaken the damage from gouging. Based on simulation analysis, $\mathrm{Li}[10]$ et al. found that higher yield strength rail material and rational hook angle can reduce the impact of gouging. Tachau [11] et al. proposed a gouging model, which described gouging as a process of small angle shocking at high velocity. Calculation showed that the gouging initiation not only needed the existence of asperities, but also needed space between armature and rails. Jin [12] et al. found that gouging size was determined by the armature velocity, the armature length and the initial temperature, while interface load had little effect on gouging size. Higher armature velocity, longer armature length and higher initial temperature would lead to bigger gouging size. Laird [13]et al. studied the effect of rail temperature on gouging and found that higher rail temperature would result in deeper gouging crater, while the depth of gouging crater decreased above $2000 \mathrm{~K}$. Laird attributed gouging to combined effect of plastic deformation of rails, thermal softening of rails and the normal velocity of armature.

\section{The Arc Erosion of Copper Alloys during Electromagnetic Launching}

Arc erosion is one of the principal technical challenges that degrade the lifetime, accuracy of the launcher. Arc erosion occurring in the initial stage, is due to local melting affiliating by resistive heating owing to velocity skin effect. Designing reasonable armature and rail structure is one way that can effectively lower the damage of arc erosion. Tao [14] et al. found that designing multilayer rail can reduce arc erosion based on simulation analysis results. Qin [15] et al. discovered that the arc erosion can be reduced by applying an external magnetic field. Chen [16] et al. found that increasing the resistivity of rails and reducing the height of rails can reduce the arc erosion.

Coating refractory metal, such as W, Mo on the surface of copper alloy launchers is another way that can reduce the impact of arc erosion. After 70 shots in plasma armature launchers operating at the $500 \mathrm{kA} / \mathrm{cm}$ liner rail current densities, weight loss per shot of the Mo coating rails was only one fiftieth of that of bare $\mathrm{Cu}$ rails [17]. Some microcracks were found on the surface of Mo coating rails, while porous structure of molten layer was found on surface of bare $\mathrm{Cu}$ rails. So Mo coating can improve the resistance ability against arc erosion, but the plasticity should be solved.

\section{Technical Methods to Solve the Surface Transient Damage of Copper Alloys}

From above discussion, it can be concluded that the solutions of the surface transient damage of copper alloys are very complicated and rather challenging. High arc erosion resistance, high strength and high conductivity are simultaneous required. It is known that increasing arc erosion resistance or strength often cause the deterioration of conductivity. For grooving and gouging at accelerating and uniform stages, enhancing the strength and conductivity of copper alloys is more important. For arc erosion at the startup stage, improving the arc erosion resistance of copper alloys is the critical topic.

\section{Designing New High Strength and High Conductivity Copper Alloys}

Other than some methods increasing the strength at the expanse of conductivity, precipitation hardening can improve the strength of copper alloys while retain high conductivity. Precipitation 
hardening and coherent twin grain refinement can improve the tensile strength while maintain a high electrical conductivity. A Cu- $0.8 \mathrm{Cr}-0.08 \mathrm{Zr}$ alloy with $200 \mathrm{~nm}$ ultrafine structure was produced by combing equal-channel angular pressing and aging [18]. A tensile strength of $688 \mathrm{MPa}$ and an electrical conductivity of $71 \%$ IACS was achieved in this copper alloy. Vinogradov[19]et al. prepared $\mathrm{CuCrZr}$ alloy with a tensile strength of $700 \mathrm{MPa}$ and an electrical conductivity of 71\%IACS by equal-channel angular pressing and aging The nanostructured $\mathrm{CuCrZr}$ alloy with a tensile strength of $700 \mathrm{MPa}$ and an electrical conductivity of 78.5\%IACS was prepared by L.X. Sun et al. ${ }^{[20]}$ using dynamic plastic deformation at low temperature. $\mathrm{Cu}-2.5 \mathrm{Ti}-0.625 \mathrm{C}$ alloy with at ensile strength of $645 \mathrm{MPa}$ and an electrical conductivity of $82 \%$ IACS was achieved by F. L. Wang et al. [21] using two-step milling, spark plasma sintering and hot pressing process.

\section{Designing Composite Structure and Applying Surface Hardening Treatment to Copper Alloys}

Designing composite structure with an electrically conductive matrix and a durable surface layer can maximize the magnetic energy and durability of rails, but the adhesion between coating and matrix as well as the plasticity of coatings should be paid more attention to overcome. Based on tradeoff of magnetic energy and durability of 505 materials, M. J. Siopiset al. [22] concluded that the refractory metals of tungsten, chromium, nickel, tantalum and molybdenum were the top candidates as coating materials. Among these refractory metals as shown in Table 1, Molybdenum has the lower electrical resistivity and good grooving resistance, but rather low gouge and fracture resistance.

Table 1 Material rankings based on each individual from of da mage [22]

\begin{tabular}{|l|l|l|}
\hline damage mechanism & metric & ranking(high to low) \\
\hline Gouging & $\sigma_{\text {uts }} / \rho$ & W, Co, Cr, Ni, Steel, Mo, Nb, Ta \\
\hline Grooving & $\rho \mathrm{C}_{\mathrm{p}} \mathrm{T}_{\text {melt }}$ & $\mathrm{W}, \mathrm{Mo}, \mathrm{Ta}, \mathrm{Cr}, \mathrm{Ni}, \mathrm{Co}$, Steel, Nb \\
\hline Fracture & $\varepsilon_{\mathrm{f}}$ & $\mathrm{N}, \mathrm{Cr}$, Stee $, \mathrm{Ta}, \mathrm{Nb}, \mathrm{Co}, \mathrm{W}, \mathrm{Mo}$ \\
\hline
\end{tabular}

M. A. Bourhamet al. [23] conducted erosion tests of pure metals and coatings at heat fluxes $33 \mathrm{GW} / \mathrm{m}^{2}$ over $100 \mu \mathrm{s}$. Arc cast molybdenum shows better thermal resistance than sintered molybdenum. Sharp deep cracks were observed on sintered molybdenum, while smoother cracks formed on the surface of arc cast molybdenum. The erosion depth of Mo coating on copper matrix was $0.5784 \mu \mathrm{m} / \mathrm{GW} \cdot \mathrm{m}^{-2}$, while the erosion depth of pure copper was $1.9717 \mu \mathrm{m} / \mathrm{GW} \cdot \mathrm{m}^{-2}$. The erosion depth of Mo coating was only $29 \%$ of that of pure copper, and microcracks were found on the surface of Mo coating.

\section{Conclusions}

With the development of high velocity electrical contacts, the transient damage problems of sliding electrical contactin electromagnetic launching were paid more and more attention. The transient of damage process, coupling effect of multiphysical fields and complexity of damage types make the damage study of copper alloys full of challenge. For studying the mechanism of transient damage and relevant factors to inhibit the damage, some important topics are proposed as followed:

(1) Studying the physical mechanism of transient damage by combining simulation method withexperiment technique.

(2) Developing new electromagnetic launching simulation installation, data collecting instrument and damage analyzing technique.

(3) Designing composite structure and performing surface hardening treatment to synthesize copper rails with high strength, high conductivity and erosion resistance. 


\section{Acknowledgments}

This work was supported by natural science foundation of Ningbo 2014A610056..

\section{References}

[1] R. M.Gee, C. Persad, The response of different copper alloys as rail contacts at the breech of an electromagnetic launcher, IEEE Trans. Magn. 37 (2001) 263-268.

[2] T. Watt, F. Stefani, M. Crawford, H. Mark, and J. Parker, Investigation of damage to solid-armature railguns at startup, IEEE Trans. Magn. 43 (2007) 214-218.

[3] R. A. Meger, K. Cooper, H. Jones, J. Neri, S. Qadri, I. L. Singer, J. Sprague, and K. J. Wahl, Analysis of rail surfaces from a multishot railgun, IEEE Trans. Magn. 41 (2005) 211-213.

[4] K. P. Cooper, H. Jones, and R. A. Meger, Analysis of railgun barrel materials, IEEE Trans. Magn. 43 (2007) 120-125.

[5] R. G. Zhu, B. Lei, Z. Y. Li, Q. Q. Tao, Production feature and current research and current research status of rail gouging, Value Eng. 6 (2012) 36-37.

[6] F. Stefani, J. Parker, Experiments to measure gouging threshold velocity for various metals against copper, IEEE Trans. Magn. 35 (1999) 312-316.

[7] K. R. Tarcza, W. F. Weldom, Metal gouging at low relative sliding velocities, Wear 209 (1997) 21-30.

[8] T. J. Watt, C. E. Clay, P. M. Bassett, D. L. Bourell, The effect of surface indentation on gouing in railguns, Wear 310 (2014) 41-50.

[9] L. M. Barker, T. G. Trucano, A. R. Susoeff, Railgun rail gouging by hypervelocity sliding contact, IEEE Trans. Magn. 25 (1989) 83-87.

[10]H. Li, B. Lei, Z. Y. Li, Q. A. Li, R. G. Zhu, Gouge formation on rail of railgun and its parameters research, Machine design and research 29 (2013) 99-102.

[11] R. D. M. Tachau, An investigation of gouge initiation in high-velocity sliding contact, Sandia National Laboratories ReportSAND91-1732-UC-706 (1991) 23-24.

[12] L. W. Jin, B. Lei, Q. Zhang,Formation mechanism and simulation analysis of railgun gouging under shock load, Journal of gun launch and control2 (2013) 13-16.

[13] D. J. Laird, The investigation of hypervelocity gouging,Storming Media, Ohio, 2002.

[14] Q. Q. Tao, X. C. Lu, Q. G. Lu, H. Li, The structure design and finite element analysis on rail launcher to depress the discharge and ablation,Journal of Projectiles, Rockets, Missiles and Guidance 31 (2011) 158-161.

[15] S. H. Qin, X. L. Yan, L. C. Chen, J. Y. Zou, The erosion of electrode surfaces in Railguns,J. Huazhong Univ. of Sci. and Tech. 28 (2000) 12-14.

[16] L. X. Chen, Z. Xiao, S. G. Xia, D. Feng, J. J. He,Effect of rail resistivity and structure on initial erosion of electromagnetic railgun, Annual meeting ofCSEE, 2010.

[17] S. N. Rosenwasser, Recent advances in large railgun structures and materials technology, IEEE Trans. Magn. 27 (1995) 444-451.

[18] G. Purcek, H. Yanar, M. Demirtas, Y. Alemdag, D. V. Shangina, S. V. Dobatkin, Optimization of strength, ductility and electrical conductivity of $\mathrm{Cu}-\mathrm{Cr}-\mathrm{Zr}$ alloy by combing multi-rout ECAP and aging, Mater. Sci. Eng. A 649 (2016) 114-122. 
[19] A. Vinogradov, V. Patlan, Y. Suzuki, K. Kitagawa, V. L. Kopylov,Structure and properties of ultra-fine grain $\mathrm{Cu}-\mathrm{Cr}-\mathrm{Zr}$ alloy produced by equal-channel angular pressing, ActaMater. 50 (2002) 1639-1651.

[20] L. X. Sun, N. R. Tao, K. Lu, A high strength and high electrical conductivity bulk CuCrZr alloy with nanotwins,Scripta Mater.99 (2005) 73-76.

[21] F. L. Wang F L, Y. P. Li, K. Wakoh, Y. Koizumi, A. Chiba, Cu-Ti-C alloy with high strength and high electrical conductivity prepared by two-step ball-milling processes,Mater.Des. 61 (2014) 70-74.

[22] M. J. Siopis, R. W. Neu, Materials selection exercise for electromagnetic launcher rails, IEEE Trans. Magn.49 (2013) 4831-4838.

[23] M. A. Bourham, J. G. Gilligan, M. L. Huebschman, D. Lianos, P. D. Aalto, Review of component erosion in electric launcher technology, IEEE Trans. Magn. 31 (1995) 678-683. 